Supplement of Atmos. Chem. Phys., 15, 6087-6100, 2015

http://www.atmos-chem-phys.net/15/6087/2015/

doi:10.5194/acp-15-6087-2015-supplement

(C) Author(s) 2015. CC Attribution 3.0 License.

(c) (i)

Supplement of

\title{
Photochemical processing of aqueous atmospheric brown carbon
}

R. Zhao et al.

Correspondence to: J. P. D. Abbatt (jabbatt@chem.utoronto.ca)

The copyright of individual parts of the supplement might differ from the CC-BY 3.0 licence. 


\section{S1. Determination of Photon Flux in the Solar Simulator}

The output of the solar simulator was recorded using the detector of the liquid waveguide capillary UVVis spectrometer described in the main article Section 2.2. This method qualitatively determines the spectral shape of the simulated sunlight.

Meanwhile, chemical actinometry using 2-nitrobenzaldehyde (2NB) was employed to quantitatively evaluate the simulated sunlight. This chemical actinometer has been employed previously by Anastasio and coworkers for quantification of photon flux in aqueous phase and ice. The absorption cross section, as well as the recommended quantum yield of this compound, are provided by Galbavy et al. (2012).

A $2 \mathrm{NB}$ solution $(200 \mathrm{uM}, 100 \mathrm{~mL}$ ) was prepared and was illuminated in the solar simulator. Aliquots were taken every two minutes for offline analyses. Measurement of 2NB was conducted using a high performance liquid chromatography (HPLC) system equipped with a Perkin Elmer Series 200 pump, a Shimadzu SPD-10A UV-Vis detector, a Waters Symmetry® C18 column (5 $\mu \mathrm{m}$ pore size, $4.6 \mathrm{~mm}$ diameter and $150 \mathrm{~mm}$ column length). A mixture of acetonitrile and water (60:40) was used as the mobile phase in isocratic mode, with a flow rate of $1 \mathrm{~mL} / \mathrm{min}$. Absorption at $256 \mathrm{~nm}$ was monitored for the detection of $2 \mathrm{NB}$.

Using the absorption cross section and recommended quantum yield of 2NB (Galbavy et al. 2010), we scaled the recorded output spectra from the solar simulator to match the observed decay rate of $2 \mathrm{NB}$. The photon flux determined this way is shown in Fig. S1, along with ambient actinic flux at the Earth's surface with a zenith angle of $0^{\circ}$ (Finlayson-Pitts and Pitts 2000).

The integrated photon flux between 290 and $380 \mathrm{~nm}$ is similar between the simulated and ambient photon flux. Although the simulator supplies more photo photons than the ambient at longer wavelengths, we assume that they are fairly similar, as we do not know what wavelengths are responsible for $\mathrm{BrC}$ photolysis (i.e. the quantum yields are unknown).

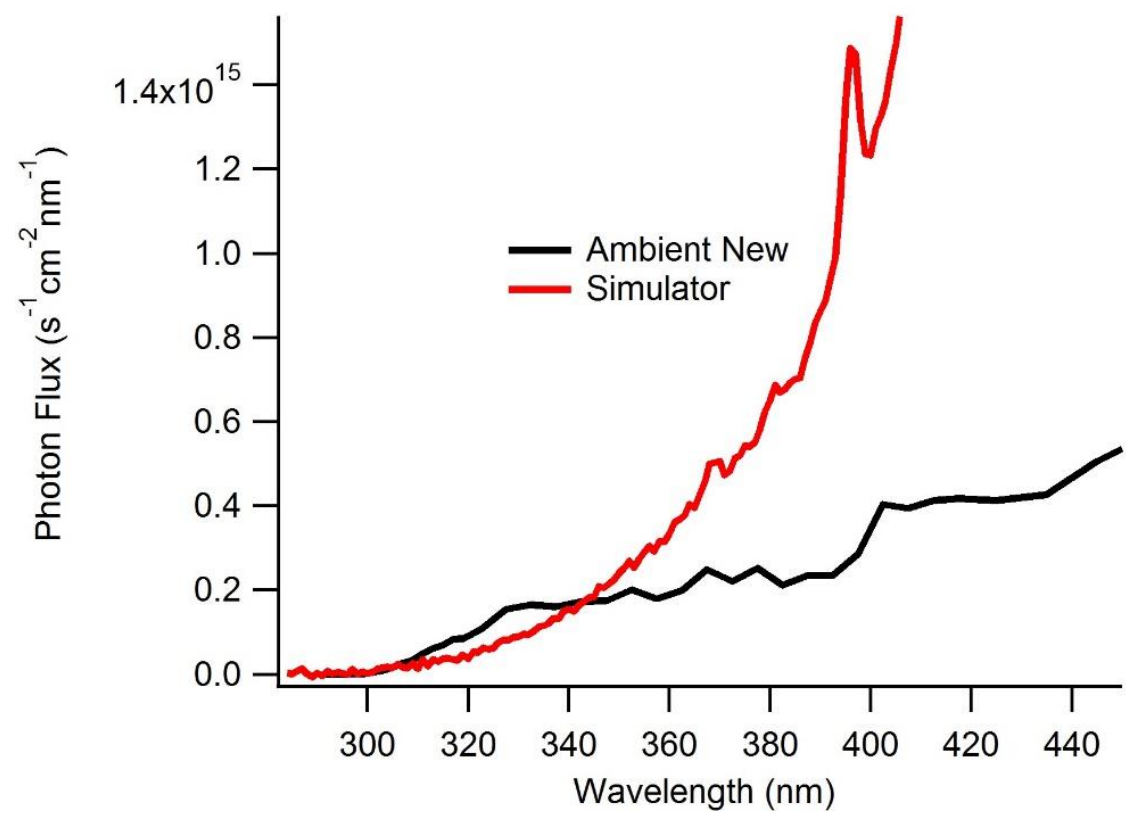

Fig. S1: The photon flux in the solar simulator and in the ambient. 


\section{S2. Quantitative Assessment of BrC Absorption}

\section{S2.1 Imine BrC}

The mass absorption coefficients (MAC) of the GLYAS and MGAS solutions were calculated. While it is difficult to estimate the amount of $\mathrm{BrC}$ in the solution, we used the total organic carbon (TOC) content of the solution to calculate MAC. The concentrated stock solutions of GLYAS and MGAS were diluted by a factor of 100, and the TOC content of the diluted solutions was measured using a Shimadzu TOC-ICPH Total Organic Analyzer. The wavelength dependent $\mathrm{MAC}_{(\lambda)}$ is calculated based on Eqn. S1 (Lee et al. 2014):

$$
\mathrm{MAC}_{(\lambda)}=\frac{A_{(\lambda)} \times \ln (10)}{b \times C_{\text {mass }}}, \quad \text { Eqn. S1 }
$$

where $A_{(\lambda)}$ is the base-10 absorbance observed at wavelength $\lambda, b$ is the effective path length of the liquid capillary waveguide $(50 \mathrm{~cm})$, and $\mathrm{C}_{\text {mass }}$ is the mass concentration $\left(\mathrm{g} \mathrm{cm}^{-3}\right)$ of total organic carbon in the solution. The MAC $(\lambda)$ values of GLYAS and MGAS calculated using Eqn. S1 are shown in Fig. S2(a).

\section{S2.2. WSOC from Biofuel Combustion Samples}

Calculations of the MAC for the biofuel combustion samples are conducted based on the organic matter $(\mathrm{OM})$ contents measured by an OM/OC method described by Chan et al. (2010). $\mathrm{MAC}_{(\lambda)}$ was calculated similar to Imine BrC using Eqn. S1 and is shown in Fig. S2(b). We consider the MAC determined in the current method a lower limit for these sample because: 1) particles freshly emitted from BB likely contain a large fraction of non-light absorbing organic compounds (Chen and Bond 2010), and 2) WSOC presents only a fraction of the total OM content of the particle, and the extraction efficiency is unknown.

The Angstrom absorption coefficients (AAE) between $290 \mathrm{~nm}$ and $480 \mathrm{~nm}$ were calculated using Eqn. S2 (Chen and Bond 2010) and are reported in the main article:

$$
A A E=\frac{\ln \left({ }^{M A C(\lambda 1)} / M A C(\lambda 2)\right.}{\ln (\lambda 1 / \lambda 2)} .
$$

\section{S2.3. Nitrophenols}

Since the nitrophenols are pure compounds, their wavelength dependent molar absorptivity $\left(\varepsilon_{(\lambda)}\right)$ and absorption cross section $\left(\sigma_{(\lambda)}\right)$ are calculated based on Eqn. S3 and S4, respectively.

$$
\begin{array}{cc}
\mathcal{E}_{(\lambda)}=\frac{A_{(\lambda)}}{c \times b} & \text { Eqn. S3 } \\
\sigma_{(\lambda)}=1.66 \times 10^{-21} \varepsilon & \text { Eqn. S4 }
\end{array}
$$

Eqn. S3 is based on the Beer-Lambert law, where $A_{(\lambda)}$ is the base-10 absorbance observed at wavelength $\lambda, \mathrm{c}$ is the molarity of the nitrophenol $(\mathrm{M})$, and $\mathrm{b}$ is the effective path length of the liquid capillary waveguide $(50 \mathrm{~cm})$. Eqn. S4 converts $\varepsilon_{(\lambda)}$ to $\sigma_{(\lambda)}$ (both in base 10) (Finlayson-Pitts and Pitts, 2000). The calculated $\varepsilon_{(\lambda)}$ and $\sigma_{(\lambda)}$ are displayed in Fig. S2(c). 

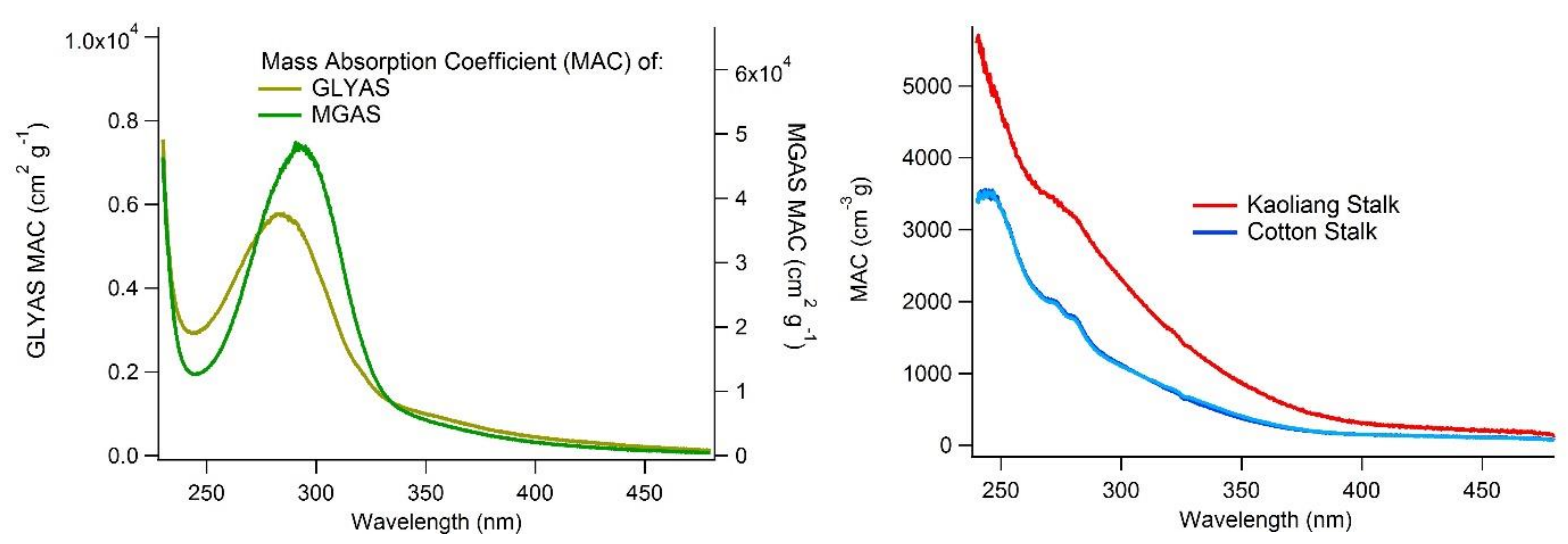

c)

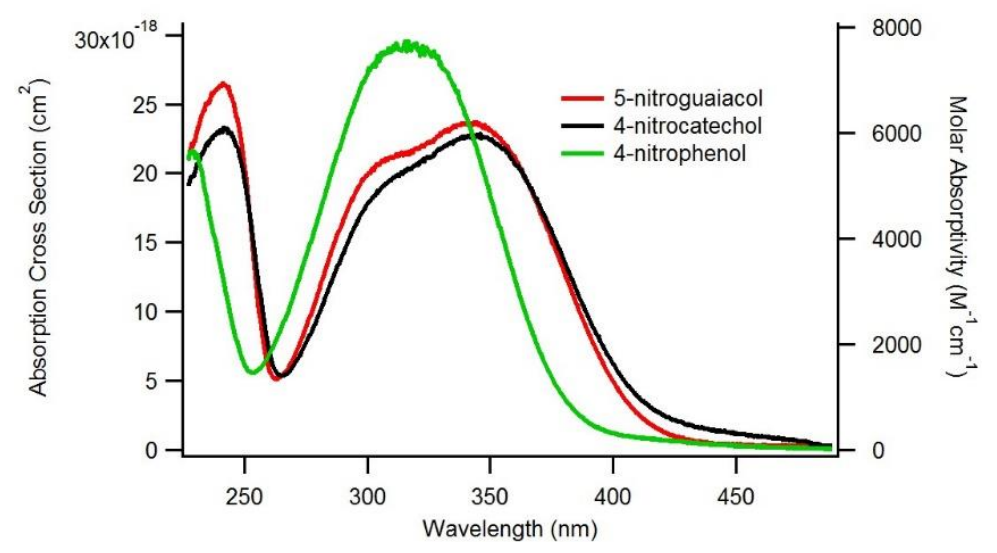

Fig. S2: Wavelength dependent mass absorption coefficient (MAC) for the Imine BrC (a), the WSOC from biofuel combustion samples (b), and the base 10 absorption cross section and molar absorptivity of the nitrophenols (c).

\section{S3. Concentration Dependence of Imine BrC Decay Rate}
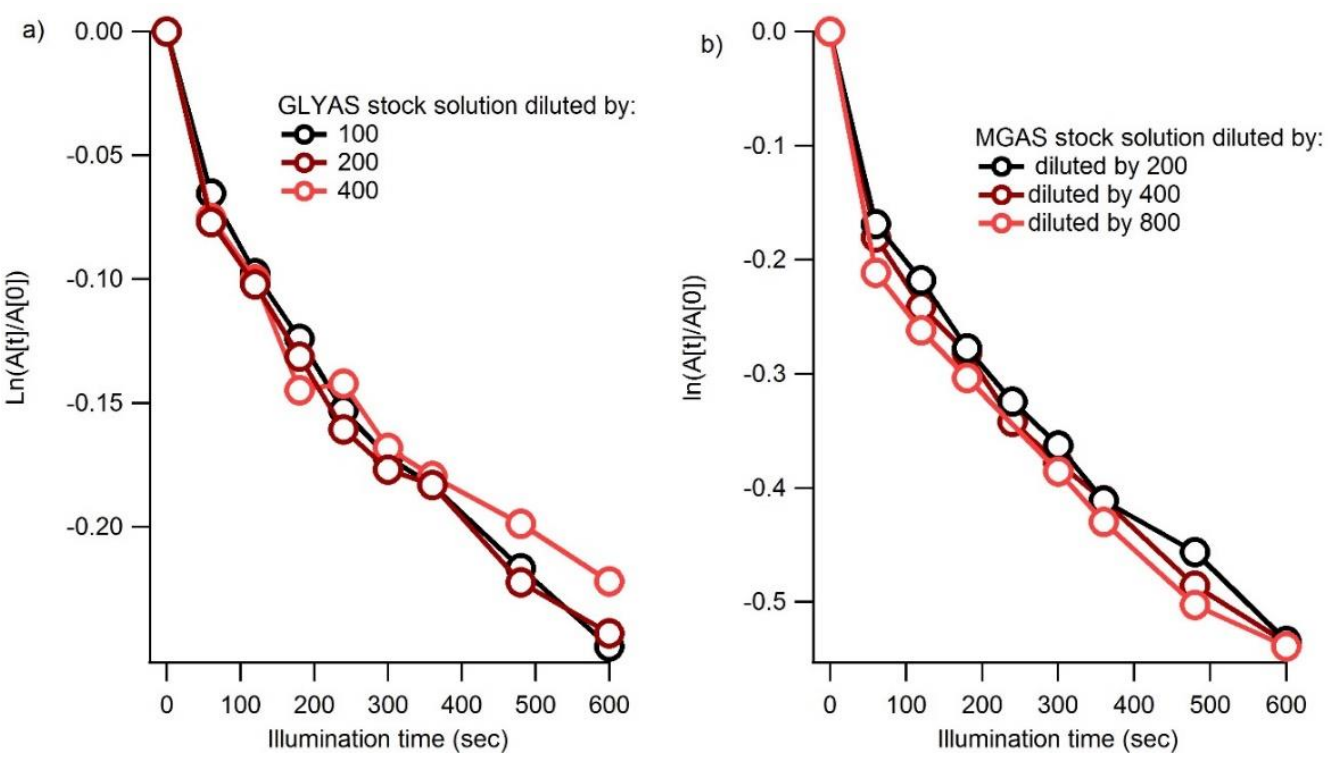
Fig. S3: Decay of the GLYAS solution (a) and the MGAS solution (b) during the first 10 min of illumination at different initial concentrations.

\section{S4. Spectral Change of 4NP and 5NG during Direct Photolysis}

a)

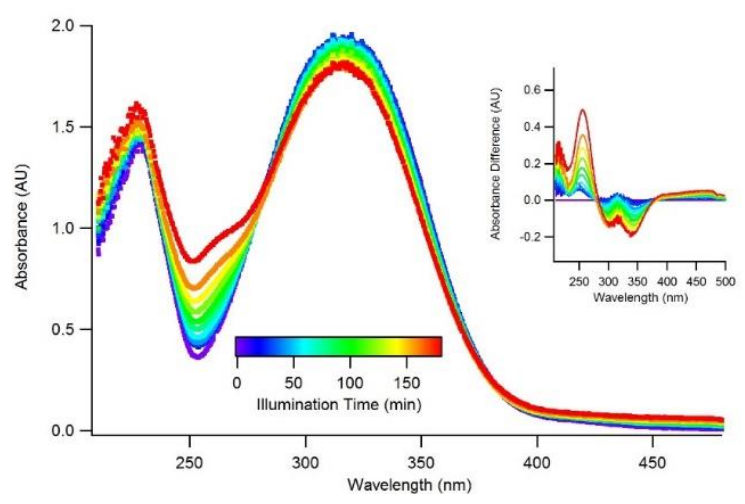

b)

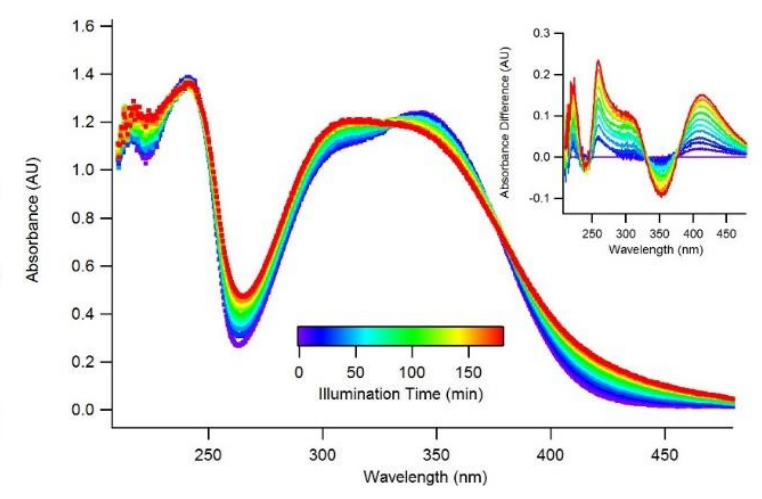

Fig. S4: Spectral change observed for a 4NP solution (a) and a 5NG solution (b) during direct photolysis experiments. The initial concentrations of $4 \mathrm{NP}$ and $5 \mathrm{NG}$ were $5 \mu \mathrm{M}$ and $4 \mu \mathrm{M}$, respectively. The insets illustrate the absorbance change compared to the initial conditions.

\section{S5. pH Dependent Photo-enhancement of 4NP and 5NG and OH Scavenger Experiments}

We investigated the photo-enhancement of the nitrophenols at solution $\mathrm{pH}$ of 3,4 and 5. We also conducted an $\mathrm{OH}$ scavenger experiment where glyoxal $(1 \mathrm{mM})$ was added to a $\mathrm{pH} 5$ solution to react $\mathrm{OH}$ radicals away.

The $\mathrm{OH}$ scavenger experiment affects the photo-enhancement rate of 4NP, but did not completely shut down the reaction. $5 \mathrm{NG}$ was not affected by the $\mathrm{OH}$ scavenger. The photo-enhancement rate of $4 \mathrm{NP}$ at $420 \mathrm{~nm}$ exhibited irregularity (Fig. S5(a)), perhaps due to the fact that $420 \mathrm{~nm}$ was close to the isosbestic point of 4NP absorption. When we plotted the photo-enhancement of 4NP at a longer wavelength, 450 nm (Fig. S5(b)), we observed a clearer $\mathrm{pH}$ dependence. 5NG exhibited a unique $\mathrm{pH}$ dependence (Fig. $\mathrm{S} 5(\mathrm{c}))$, where the photo-enhancement was suppressed significantly when the $\mathrm{pH}$ was 3.

For $4 \mathrm{NP}$ and $5 \mathrm{NG}$, the formation of color exhibited strong linearity in time, which prevented us from fitting a $1^{\text {st }}$ order growth curve to extract $\mathrm{k}_{\text {direct. }}^{\mathrm{I}}$ Therefore, we decided to present the rate of photoenhancement ( $\left.\mathrm{k}_{\text {direct }}\right)$ in an absorbance based manner using Eqn. S5 in units of [AU $\mathrm{M}^{-1} \mathrm{~s}^{-1}$ ]:

$$
\mathrm{k}_{\text {direct }}^{*}=\mathrm{S} / 60 \times \mathrm{C}_{\mathrm{ini}}
$$

where $\mathrm{S}\left(\mathrm{AU} \mathrm{min} \mathrm{m}^{-1}\right)$ is the initial slope of color formation found from Fig. S5, 60 is the conversion factor from minutes to seconds, and $\mathrm{C}_{\mathrm{ini}}(\mathrm{M})$ is the initial concentration of the nitrophenol. The $\mathrm{k}_{\text {direct }}$ values obtained are summarized in Table S1. If the identity and molar absorptivity of the reaction products are determined from future studies, these absorbance based rate constants can be converted into concentration based constants.

Table S1: The absorbance based $1^{\text {st }}$ order rate constant of photo-enhancement

\begin{tabular}{llllll} 
& & \multicolumn{4}{c}{$\mathrm{k}^{*}$ direct $\left(\mathrm{AU} \mathrm{M}^{-1} \mathrm{~s}^{-1}\right)$} \\
\cline { 3 - 6 } Compound & $\mathrm{C}_{\mathrm{ini}}(\mu \mathrm{M})$ & $\mathrm{pH} 3$ & $\mathrm{pH} 4$ & $\mathrm{pH} 5$ & $\mathrm{pH} 5 \mathrm{OH}$ scav. \\
\hline
\end{tabular}




$\begin{array}{lccccc}4 \mathrm{NP}(420 \mathrm{~nm}) & 15 & 0.68 & 0.62 & 0.40 & 0.24 \\ 4 \mathrm{NP}(450 \mathrm{~nm}) & 15 & 0.37 & 0.47 & 0.64 & 0.47 \\ 5 \mathrm{NG}(420 \mathrm{~nm}) & 8 & 2.7 & 4.0 & 4.8 & 4.8\end{array}$
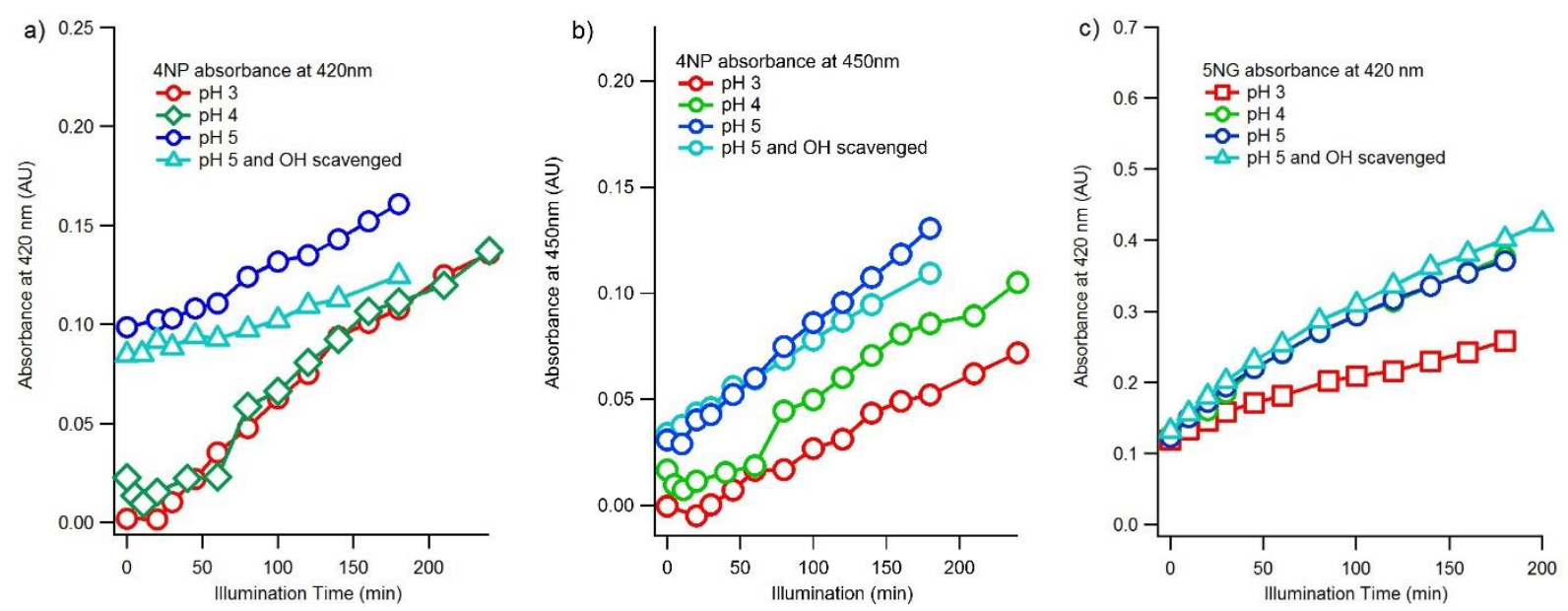

Fig. S5: Color formation from 4NP and 5NG solutions during the $\mathrm{pH}$ dependent and the $\mathrm{OH}$ scavenger experiments. The formation profiles of absorbance at $420 \mathrm{~nm}$ and $450 \mathrm{~nm}$ from $4 \mathrm{NP}$ are shown in (a) and (b). The formation profiles of absorbance at $420 \mathrm{~nm}$ from $5 \mathrm{NG}$ are shown in (c).

\section{S6. pH Dependent Absorption of Nitrophenols}
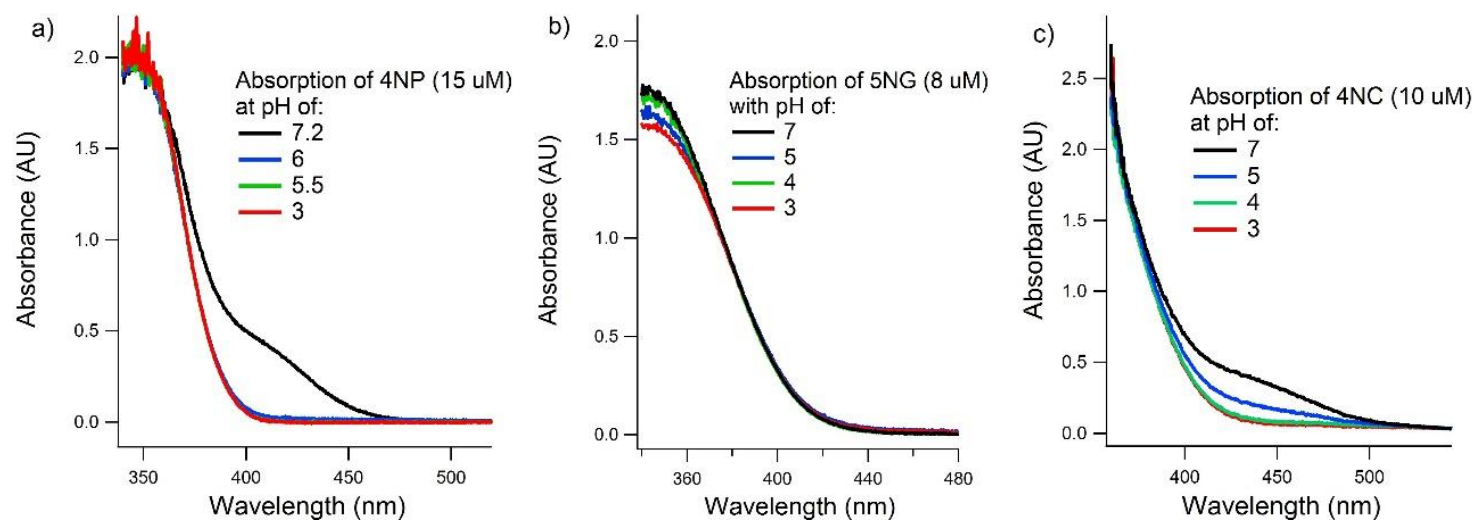

Fig. S6: Absorption spectra of 4NP (a), 5NG (b) and 4NC (c) at various solution pH values.

\section{S7. Photooxidation of 4NP and 5NG}



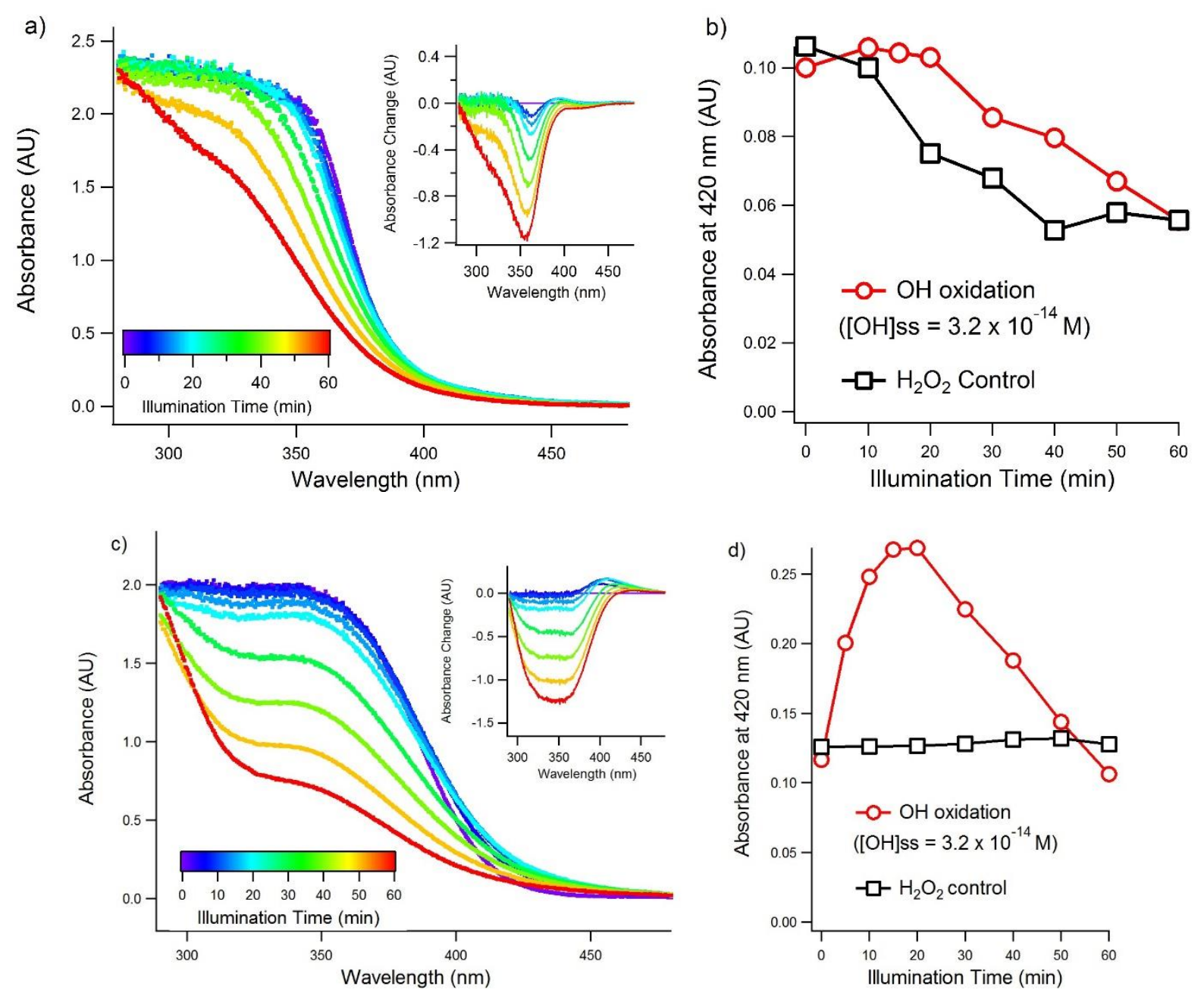

Fig. S7: The spectral change of 4NP and 5NG solutions during $\mathrm{OH}$ oxidation experiments are shown in (a) and (c). The time profiles of absorbance at $420 \mathrm{~nm}$ for $4 \mathrm{NP}$ and $5 \mathrm{NG}$ are shown in (b) and (d). In (b) and (d), the black traces represent $\mathrm{H}_{2} \mathrm{O}_{2}$ control experiments, while the red traces represent $\mathrm{OH}$ oxidation experiments. The concentration of $4 \mathrm{NP}$ and $5 \mathrm{NG}$ solutions are $15 \mu \mathrm{M}$ and $8 \mu \mathrm{M}$, respectively.

\section{S8. Simple Kinetic Model Applied to 4NP and 5NG}

In this model, the precursor nitrophenols undergo prescribed pseudo- $1^{\text {st }}$ order decay with a $[\mathrm{OH}] \mathrm{ss}$ of 3.2 $\times 10^{-14} \mathrm{M}$. For the case of 4NP we also observed direct loss by photolysis (Fig. S7(b)) by the $254 \mathrm{~nm}$ lamp with a rate constant of $2.6 \times 10^{-4} \mathrm{~s}^{-1}$. This direct photolysis was also added to the prescribed decay of 4NP. The $2^{\text {nd }}$ order rate constant of 4NP was adopted from Einschlag et al. (2003): $6.2 \times 10^{9} \mathrm{M}^{-1} \mathrm{~s}^{-1}$.

Although the $\mathrm{OH}$ reactivity of $5 \mathrm{NG}$ and $4 \mathrm{NC}$ in the aqueous phase is not available in the literature, we used $1 \times 10^{10} \mathrm{M}^{-1} \mathrm{~s}^{-1}$ as a rough estimate for these two compounds. This estimation is based on the fact that the additional methoxy and hydroxy functional groups on $5 \mathrm{NG}$ and $4 \mathrm{NC}$ are electron donating and can likely enhance the $\mathrm{OH}$ reactivity. The model results for sample 4NP and $5 \mathrm{NG} \mathrm{OH}$ oxidation experiments are shown in Fig. S8. 

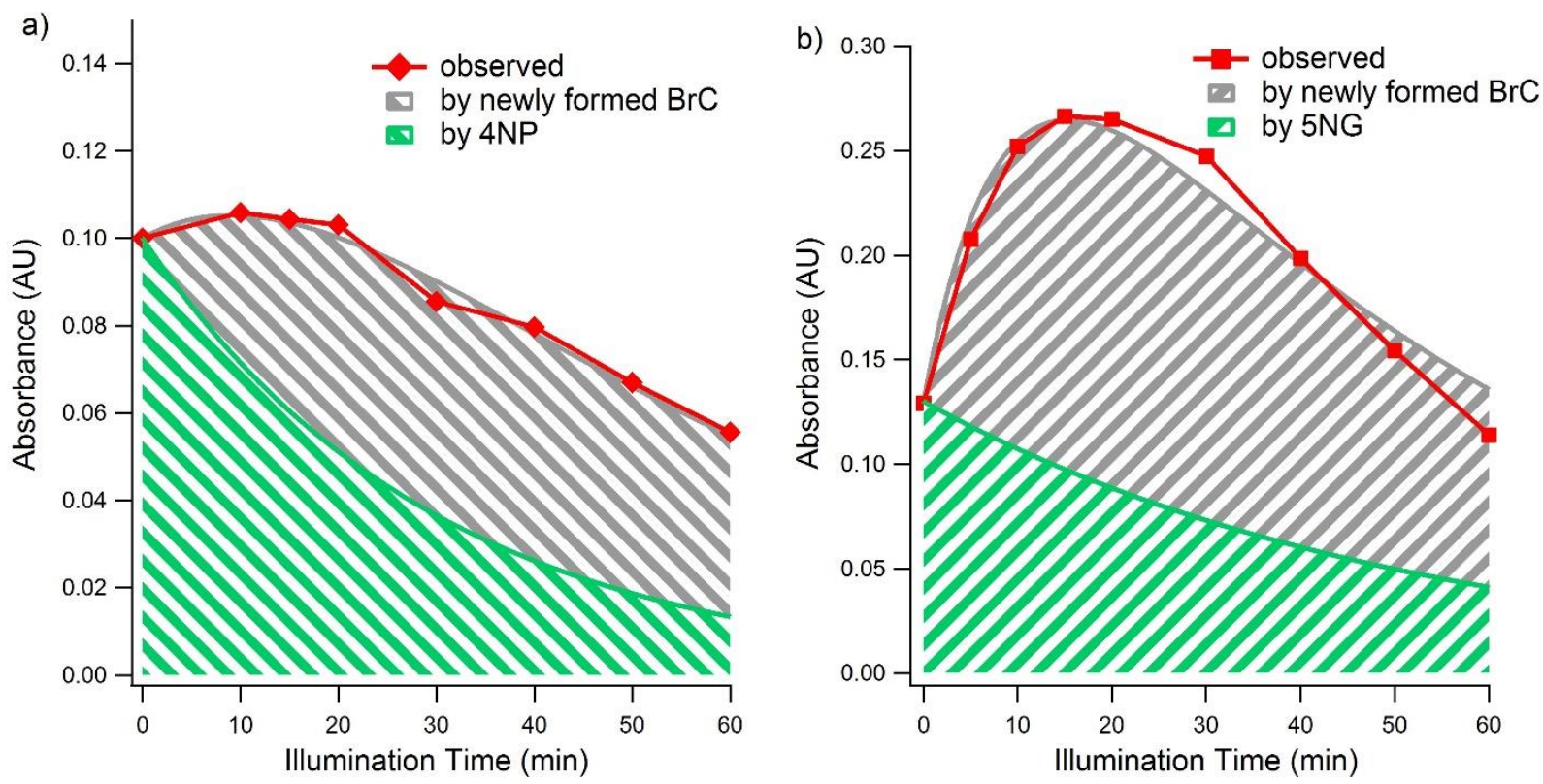

Fig. S8: The simple kinetic model applied to one example experiment each of 4NP (a) and 5NG (b) $\mathrm{OH}$ oxidation. The shaded areas are the simulated contribution of a newly formed colored product and the decay precursor. The red lines represent the experimental results.

\section{References:}

Chan, T. W., Huang, L., Leaitch, W. R., Sharma, S., Brook, J. R., Slowik, J. G., Abbatt, J. P. D., Brickell, P. C., Liggio, J. and Li, S.: Observations of OM/OC and specific attenuation coefficients (SAC) in ambient fine PM at a rural site in central Ontario, Canada, Atmos. Chem. Phys., 10, 2393-2411, 2010.

Chen, Y. and Bond, T.: Light absorption by organic carbon from wood combustion, Atmos. Chem. Phys., 10, 1773-1787, 2010.

Einschlag, F. S. G., Carlos, L. and Capparelli, A. L.: Competition kinetics using the UV/H2O2 process: a structure reactivity correlation for the rate constants of hydroxyl radicals toward nitroaromatic compounds., Chemosphere, 53, 1-7, 2003.

Finlayson-Pitts, B. J. and Pitts, J. N.: Chemistry of the upper and lower atmosphere : theory, experiments and applications, Academic Press, San Diego, Calif. ; London, 2000.

Galbavy, E. S., Ram, K. and Anastasio, C.: 2-Nitrobenzaldehyde as a chemical actinometer for solution and ice photochemistry, J. Photochem. Photobiol. A., 209, 186-192, 2010.

Lee, H. J., Aiona, P. K., Laskin, A., Laskin, J. and Nizkorodov, S. A.: Effect of solar radiation on the optical properties and molecular composition of laboratory proxies of atmospheric brown carbon, Environ. Sci. Technol., 48, 10217-10226, 2014. 